\title{
Mapping Rainfall Feedback to Reveal the Potential Sensitivity of Precipitation to Biological Aerosols
}

\author{
Cindy E. Morris, Samuel Soubeyrand, E. Keith Bigg, Jessie M. Creamean, and David C. Sands
}

S ynoptic-scale atmospheric circulations define the conditions in which rainfall can occur. However, for the particular set of meteorological conditions at a given site, aerosols play a vital role in the formation and quantity of precipitation by determining the number and rate at which eventual raindrops form. Cloud-active aerosols include cloud condensation nuclei (CCN) (the particles on which cloud drops form), giant cloud concentration nuclei (GCCN; $\mathrm{CCN}>2 \mu \mathrm{m}$ diameter), and ice nucleating particles (INPs), which aid the formation of ice crystals in the atmosphere. Weighing the importance of aerosols in the outcome of events leading to rainfall is a challenge because aerosols are always present under all meteorological conditions.

Bigg and colleagues (2015) suspected that for the cloud-active aerosols that are usually present only at low concentrations in the atmosphere (GCCN and certain INPs), increases in their abundance due to

AfFILIATIONS: MoRrIs-INRA, Montfavet, France, and Department of Plant Sciences and Plant Pathology, Montana State University, Bozeman, Montana; SoubeYRAND—INRA, Avignon, France; BIGG-Elanora Heights, NSW, Australia; CREAMEANCooperative Institute for Research in Environmental Sciences, Earth System Research Laboratory, NOAA, and NOAA Earth System Research Laboratory, Physical Sciences Division, Boulder, Colorado; SANDS-Department of Plant Sciences and Plant Pathology, Montana State University, Bozeman, Montana CORRESPONDING AUTHOR: Cindy E. Morris, cindy.morris@inra.fr

The abstract for this article can be found in this issue, following the table of contents.

DOI:I0.II75/BAMS-D-I5-00293.I

A supplement to this article is available online (10.II75/BAMS-D-15-00293.2)

(C)2017 American Meteorological Society rainfall could have notable effects on subsequent rainfall leading to feedback. They reasoned that the intensity of rainfall feedback and its directionality (positive or negative) could give clues about processes that would lead to persistent increases in cloud-active aerosols after a rainfall event, and would provide location-specific insight into precipitation's sensitivity to aerosols that depended on factors such as orography and land use. They developed an analytical tool to quantify an index value of rainfall feedback from changes in rainfall patterns following relatively heavy rainfall events (called "key days," as illustrated in Fig. 1) that are persistent enough to be distinguished in historical time-series data of daily precipitation (Soubeyrand et al. 2014). This index can be used to quantify feedback at precise geographic locations, to delimit regions with homogenous index values of feedback, and to identify changes in feedback over time (Bigg et al. 2015; Soubeyrand et al. 2014).

Recently, the probability of next-day precipitation following rainfall events was assessed for rainfallinduced changes in soil moisture across sites in the United States (Tuttle and Salvucci 2016). Soil moisture anomalies significantly influenced rainfall probabilities in about $40 \%$ of the studied areas, but varied from positive to negative from east to west. Although this study did not consider aerosols, it nevertheless highlights the geographic variability in rainfall feedback and the need for tools to help reveal site- or region-specific processes. If aerosols are involved in such feedbacks, it is likely that variations in cloud-active particles, their emission, aging, interaction with other aerosols, and their response to weather conditions could compound these feedbacks by inducing additional variability across geographic sites and over time. These traits of aerosols could also be influenced by regional meteorological conditions 


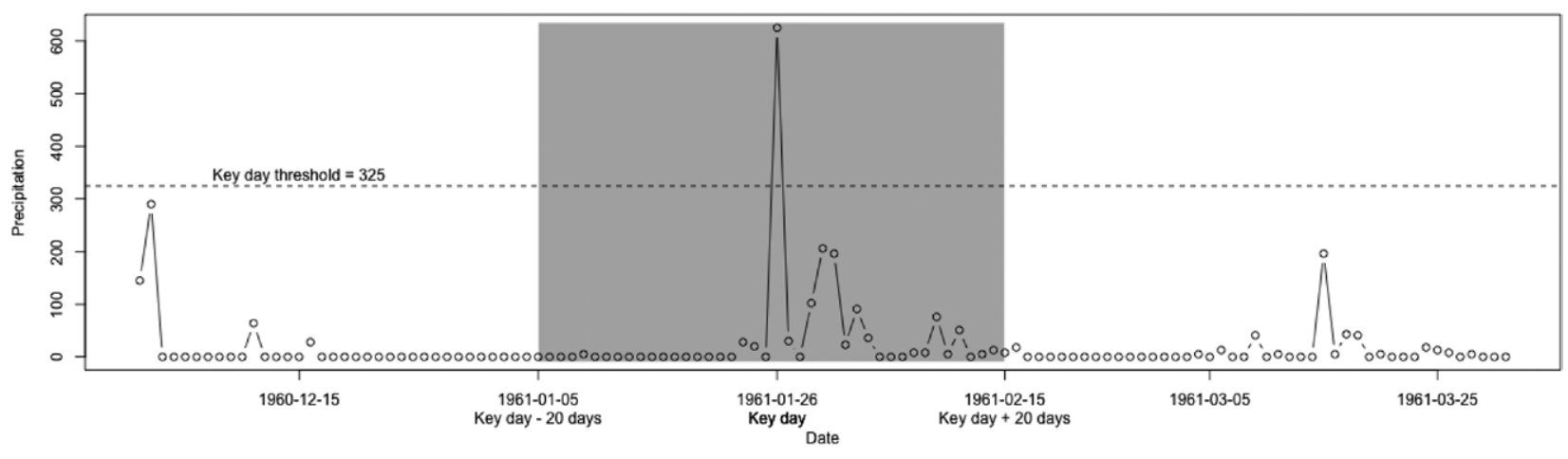

FIG I. Daily precipitation (in tenths of $\mathrm{mm}$ ) leading up to and following a key-day rainfall event of $32.5 \mathrm{~mm}$ on $2 \mathrm{I}$ Jan $196 \mathrm{I}$ from the historical records from the weather station at Winters, California (site USC00049742 in the NOAA database at www.ncdc.noaa.gov/data-access/quick-links\#ghcn). The data used to assess the intensity of rainfall feedback (FeedbackStat, $F$ ) in the $\mathbf{2 0}$ days preceding and after the key day are highlighted in gray.

(i.e., temperature, relative humidity, and dynamics). Disentangling the macrophysical meteorological factors from the aerosol microphysical effects on precipitation remains a grand challenge because meteorological conditions cannot be disassociated from the aerosol context under real field conditions. Furthermore, neither a coherent, universal approach for anticipating how aerosol traits vary among sites, nor a set of rationale for intersite comparisons of aerosol effects on precipitation to account for the different specific effects, exists to date.

Here we illustrate how maps of rainfall feedback indices can provide a framework for understanding how aerosols leverage meteorological conditions to have decisive effects on rainfall. By mapping the values of the index, hypotheses could be generated about aerosols emitted specifically from different types of land use. This would lead to criteria to choose experimental sites for testing these hypotheses. We report the characteristics of maps for data from 1,250 weather stations in the 17 states of the western continental United States, many of which are states where drought has attained unprecedented proportions. The reason for focusing on the western United States was based on not only the recent water restrictions due to drought, but also on the particular topography that fosters processes of precipitation formation due to large-scale synoptic patterns and water vapor transport, and the influence of a multitude of regional and long-range transported aerosol sources, orography, and a combination of land surface vegetation and urban development (Creamean et al. 2015; Guan et al. 2012; Hayhoe et al. 2004; Pandey et al. 1999; Ralph et al. 2013; Rauber 1992; Rosenfeld et al. 2008). These maps and the associated data are freely available at http://w3.avignon.inra.fr /rainfallfeedback/index.html, a site that also provides instructions for making maps of additional sites in other regions around the world. This website can serve as a platform to share these maps and as a tool to design experiments to test hypotheses about mechanisms underlying rainfall feedback and the sensitivity of rainfall to aerosols.

\section{CALCULATING AND MAPPING THE RAINFALL FEEDBACK INDEX. Rainfall feed-} back was assessed with the open-source $\mathrm{R}$ package FeedbackTS (http://cran.r-project.org/web/packages /FeedbackTS/), with time-series algorithms described previously (Soubeyrand et al. 2014), for freely available daily rainfall data from NOAA's National Centers of Environmental Information (www.ncdc .noaa.gov/). We accessed 90 GB of daily rainfall data from the Global Historical Climate Network on the NOAA website for weather stations having approximately 100 consecutive years of data in the 17 states of the western continental United States. There were 1,250 such sites. Rainfall feedback was assessed for rainfall occurrence and quantity as previously described (Soubeyrand et al. 2014). Significant trends in feedback were more readily identified for rainfall occurrence than for rainfall quantity; therefore, indices for feedback trends in rainfall occurrence were plotted on maps. Significance was calculated via a randomization test that yields a $p$ value (indicated in the drop-down menu for each location on the website) as described previously (Soubeyrand et al. 2014). The plotted indices correspond to the variable named $\bar{D}$ [Soubeyrand et al. 2014, Eq. (3)] multiplied by 20 and corrected for seasonal asymmetry. Modifications to 
the previously described calculation are described in this paper's online supplement. The index described here, equal to $\bar{D} \times 20$ and corrected for seasonal asymmetry, is named FeedbackStat $(F)$. Hence, the values plotted on the maps indicate the cumulative number of rainfall events in a 20 -day period after a key rain date in excess of the average number of rainfall events expected in that period. By characterizing a large number of sites as densely as possible across a region, the site-level tests can be used as indicators of regional properties independent of the statistical significance per se of each site. Hence, contour lines on the maps represent spatial trends in $F$ assessed with a geostatistical approach. Contours were obtained with universal kriging incorporating a linear trend in the coordinates (Chilès and Delfiner 1999). Briefly, kriging consists of estimating the values of a variable across space based on i) point observations of this variable spread in the study domain, and ii) a weighted average technique generally giving more weight to neighbor observations.

From the entire rainfall datasets and subsets divided into seasonal periods (spring-summer: April-September; fall-winter: October-March) and historical periods (up until 1960; after 1960), 12 maps were created that indicate the geographic distribution of $F$. The year 1960 was chosen to assess the impact of time, as this was an approximate date of intensification of a range of global changes, including industrialization, urbanization, and land use, and was linked to notable changes in rainfall feedback in Australia (Bigg et al. 2015). The trends described below concern mostly the period of January to December for the entire 100 years unless indicated otherwise and specified with subscripts for $F$. Positive values of $F$ indicate a greater number of rainfall events than expected (positive feedback). Likewise, negative values indicate negative feedback.

According to the assumptions of our model, a key day represents a rainfall event of sufficient intensity to set off the generation of aerosols as described above. However, to calculate $F$, key rainfall days must be sufficiently separated in time (Soubeyrand et al. 2014). Therefore, the rain intensity of the key days used in the calculation varied among sites because of the rainfall patterns in each data series, and is reported on the maps for each site. The constraints of the calculation limiting the number of key days have likely led to an underestimation of the magnitude of the feedbacks. Furthermore, the strongest feedback effects are likely to occur downwind of sites where a key day occurs, but are not accounted for here because the calculation of the feedback index is site-specific (i.e., is made separately for each site by exploiting rainfall data collected only at this site). We have not considered downwind relationships in feedback because this would involve geographic offsetting of the temporal relationships. Such calculations are a future challenge.

\section{TRENDS IN RAINFALL FEEDBACK PAT-} TERNS. For all 1,250 sites over the entire time period, $F$ decreased slightly from west to east across all 17 states. However, there was no trend in a meridional direction over all states (Fig. 2). The zonal trend could be in part due to storm activity along the West Coast traveling eastward with westerly wind patterns. It is difficult to elucidate the large-scale effects of rainfall feedback. However, focusing on specific hypotheses on regional scales may provide better insight into aerosol and rainfall feedback effects in the western United States.

A map of the sites with the most extreme values of $F$ (Fig. 3) $[F \geq 0.5$ (blue and lavender pins on map) or $F \leq-0.5$ (red pins)] suggested that orographic precipitation was a predisposing factor for positive feedback. For the top 50 percentile (47 sites) of the 94 sites with $F \geq 0.5,34$ (72\%) were on the windward side of mountain ranges where orographic precipitation occurs. This is in sharp contrast to the geographic context of the 29 sites with near-zero values of $F$, where $21(72 \%)$ are in the plains east of the Rocky Mountains (Fig. 3). Furthermore, 97\% (57 of 59) of the values for $F$ in California for sites between $34.65^{\circ}$ and $40.27^{\circ} \mathrm{N}$ latitude and west of the Sierra Nevada mountain range were positive, and they were among the greatest values for all 1,250 sites analyzed here. In this region, from the northern to southern limits of California's Central Valley, water resources are derived primarily from orographic precipitation during the cold season and storm systems that are typically advected and orographically ascend the Sierra Nevada and pass over San Francisco, San Jose, and Oakland (Dettinger 2011; Pandey et al. 1999). Other areas with notable densities of sites with highly positive $F$ also included the western side of the Sawtooth Mountain range north of Boise, Idaho, and the western edge of the Rocky Mountain Range from North Rim in the Grand Canyon in Arizona to Ennis, Montana. The short residence time of an air parcel within an orographic cloud means that precipitation is much more dependent on the efficiency or speed of development of precipitation than in nonorographic clouds (Letcher and Cotton 2014). Interestingly, field 

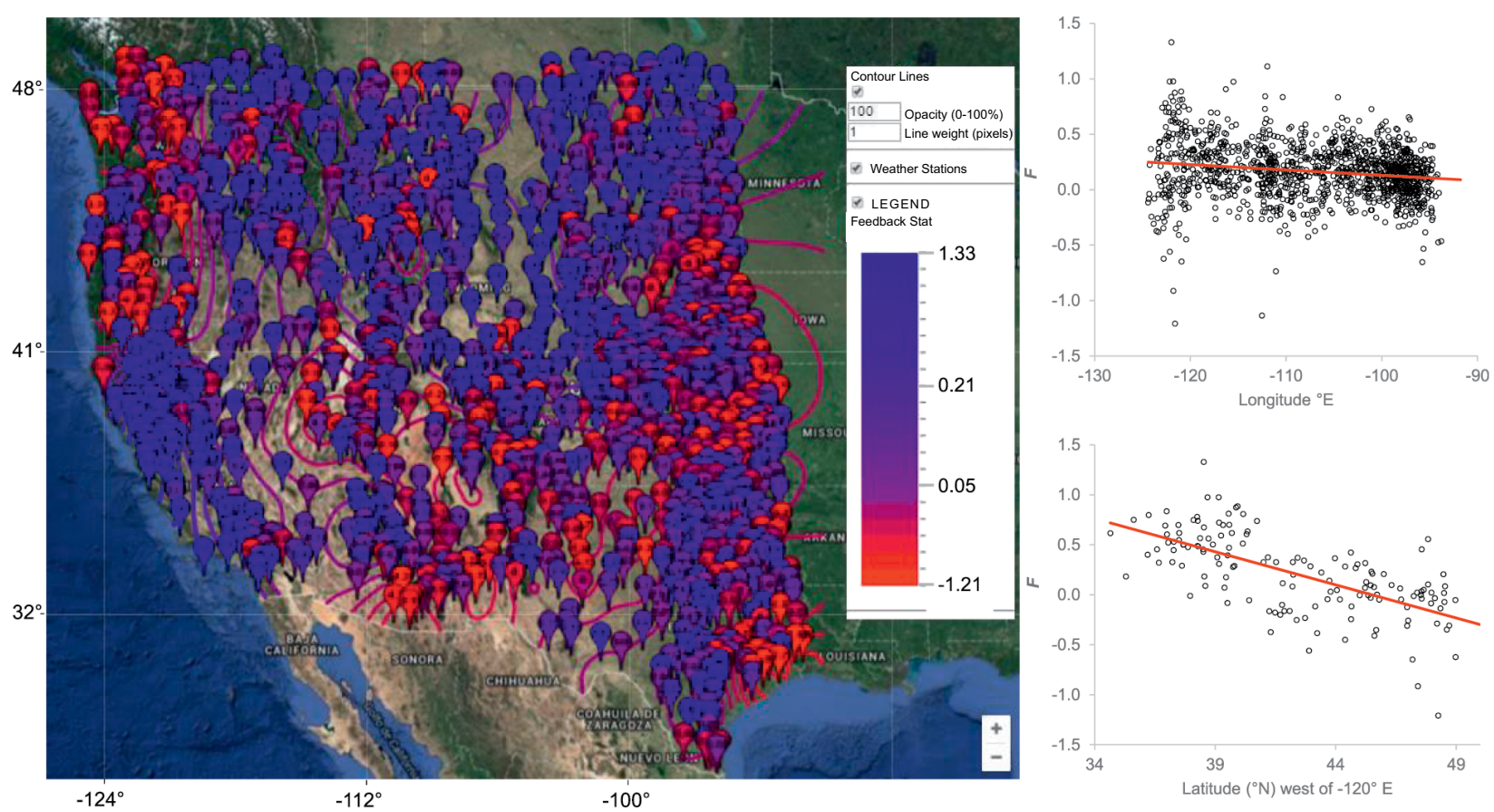

FIG 2. Trends of $F$ across the western part of the continental United States at I,250 weather stations. The left panel is a map of $F$ at each site for the entire 100 -yr period as presented on the website (http://w3.avignon inra.fr/rainfallfeedback/), with positive values in blue and negative values in red. The east-west trend in $F$ (upper right panel) shows different north-south amplitudes of $F$ depending on the region, but no overall east-west trend. The north-south trend in $F$ for sites west of $-120^{\circ} \mathrm{E}$ longitude (lower right panel) revealed a significant decrease in $F$ from north to south (The red line represents the linear regression $F=3.02-0.066 \times$ Latitude $\left.\left({ }^{\circ} \mathrm{N}\right), \mathbf{R}^{2}=0.418, p<0.00000\right)$.

observations show that INPs active at temperatures warmer than $-10^{\circ} \mathrm{C}$ (i.e., most likely biological INPs) are lost early in the precipitation history of orographic clouds (Stopelli et al. 2015).

For the sites west of $-120^{\circ} \mathrm{E}$, feedback increased significantly from north to south (Fig. 2, lower right panel), and $56 \%$ (5 out of 9 ) of the sites with the most extreme negative feedback ( $\leq-0.5$, red pins) were in Oregon and Washington (Fig. 3). This trend has also been exaggerated over time, as revealed by the significant decrease of $F_{\text {pre-1960 }}-F_{\text {post-1960 }}$ with increasing latitude (slope of the linear regression $=-0.062$, $p=0.00002$ ). Because there are distinctly different land uses north and south of $40^{\circ} \mathrm{N}$, and in particular linked to changes in the nature and health of the forests of the Pacific Northwest and to intensification of agriculture in California's Central Valley since the 1950s (Grossmann et al. 2008; Hart 2001), we explored the seasonal trends in feedback.

There were 733 sites in the database with sufficient rainfall events in both the spring-summer and the fall-winter seasons to allow us to calculate $F$ values for each season. From these, we mapped sites with the most pronounced seasonal differences in rainfall feedback, viz. those that had values of $F \geq 0.5$ in one season and negative values of $F$ in the counter season that were at least 1 unit of $F$ different from the former season (Fig. 4). There was a distinct transect from northwest to southeast. In the northwest there was high positive feedback in the spring-summer season and negative feedback in the fall-winter season. In contrast, the inverse trend prevailed toward the southeast with a transition along the western edge of the Rocky Mountain Range. This raises the question about the factors at these sites that would be favorable to rainfall during one season and inhibitory to rainfall in another season.

\section{HOW THE BIOLOGY OF AEROSOLS COULD UNDERLIE PERSISTENT RAINFALL FEEDBACK. Although aerosol} concentrations can be reduced by heavy rain, and this potentially affects subsequent rainfall during the next few days, several studies provide an alternative point of view by demonstrating that atmospheric aerosols increase after rainfall. We consider biological aerosols 


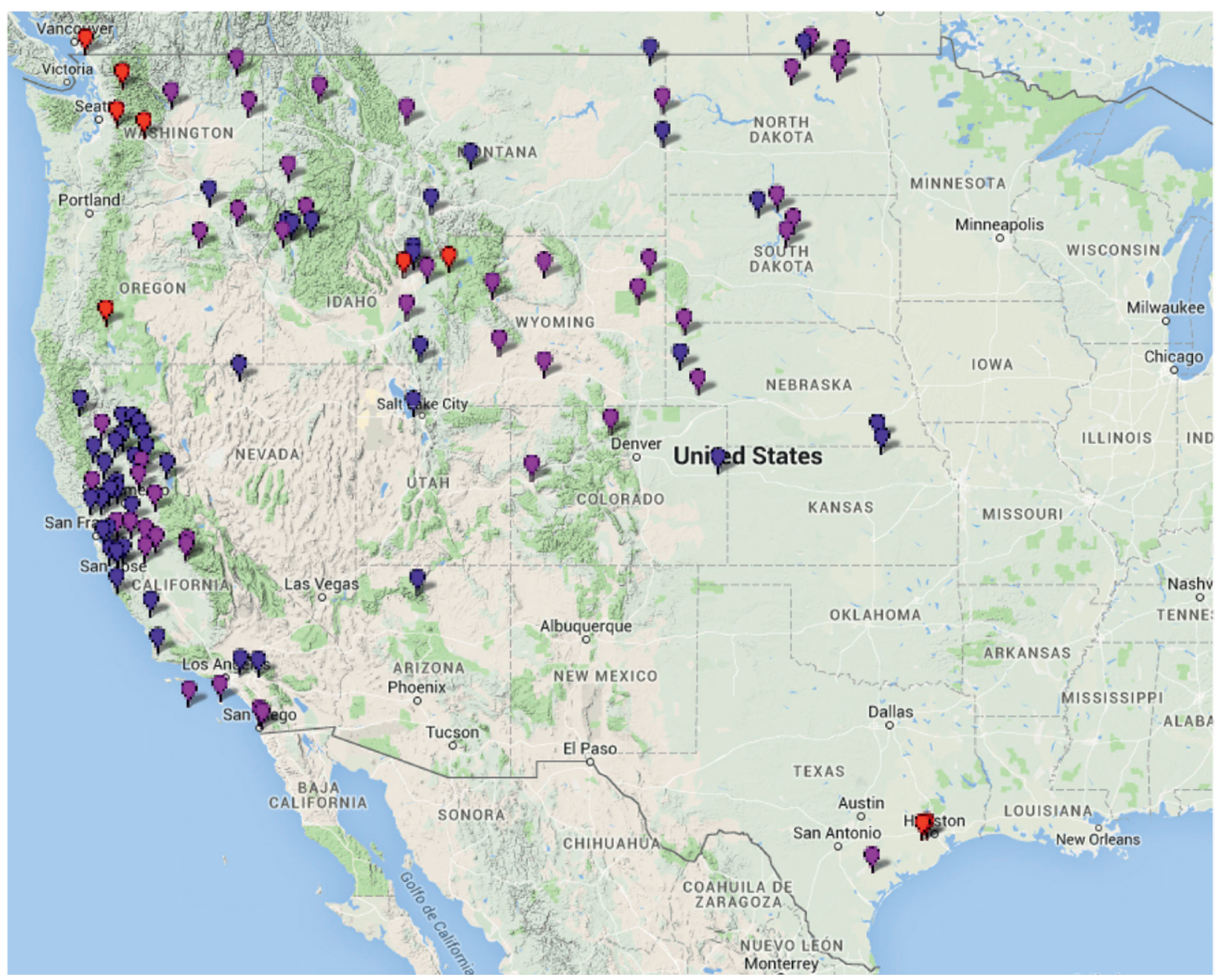

FIG 3. Location of the sites with the most positive and the most negative values of $F$. For sites labeled with blue and lavender pins, $F \geq 0.5$ : those with blue pins were in the top 50 percentile of the sites with $F \geq 0.5$ and those with lavender pins were in the bottom 50 percentile of this group of sites. For sites with red pins, $F \leq-0.5$. The map was made with GPS visualizer (www.gpsvisualizer.com/) using the Google Terrain maps background.

in particular because of i) their particular capacities and efficiencies as INPs, ii) their intimate link to land use, iii) the rapid response to water of the microorganisms that are at the origin of these aerosols, and iv) the minimal consideration that they have had as potential actors in meteorological phenomena.

Some researchers have made observations within the 24 -h period following a rain event and have noted large increases, starting within the first hour after the event, in airborne biological particles or particles containing organic matter (Huffman et al. 2013; Wright et al. 2014; Yue et al. 2016). Huffman and colleagues observed increases in INPs active at $-15^{\circ} \mathrm{C}$ on the order of 10 -fold just after rain onset, whereas Yue and colleagues assessed only biological-like particles and observed that those resembling bacteria increased two-fold. Bigg and colleagues measured aerosol dynamics over longer periods of time after rain events and observed enhancement of INPs that began early after a rain event but that persisted over about a 3-week period following certain rain events (Bigg 1958; Bigg et al. 2015). In these studies, 10 -fold increases in INPs active at $-15^{\circ} \mathrm{C}$ occurred within 2 weeks after the key rain event. These observations support the notion that rainfall events lead to a rapid increase in cloud-active aerosols-within hours of a rain event-that can persist for longer periods of up to several weeks. In further support of this potential feedback, modeling of cloud processes showed that increases in accumulated precipitation at ground level occurred within a week when insoluble organic aerosols were increased by a factor of about 10 (Phillips et al. 2009). 


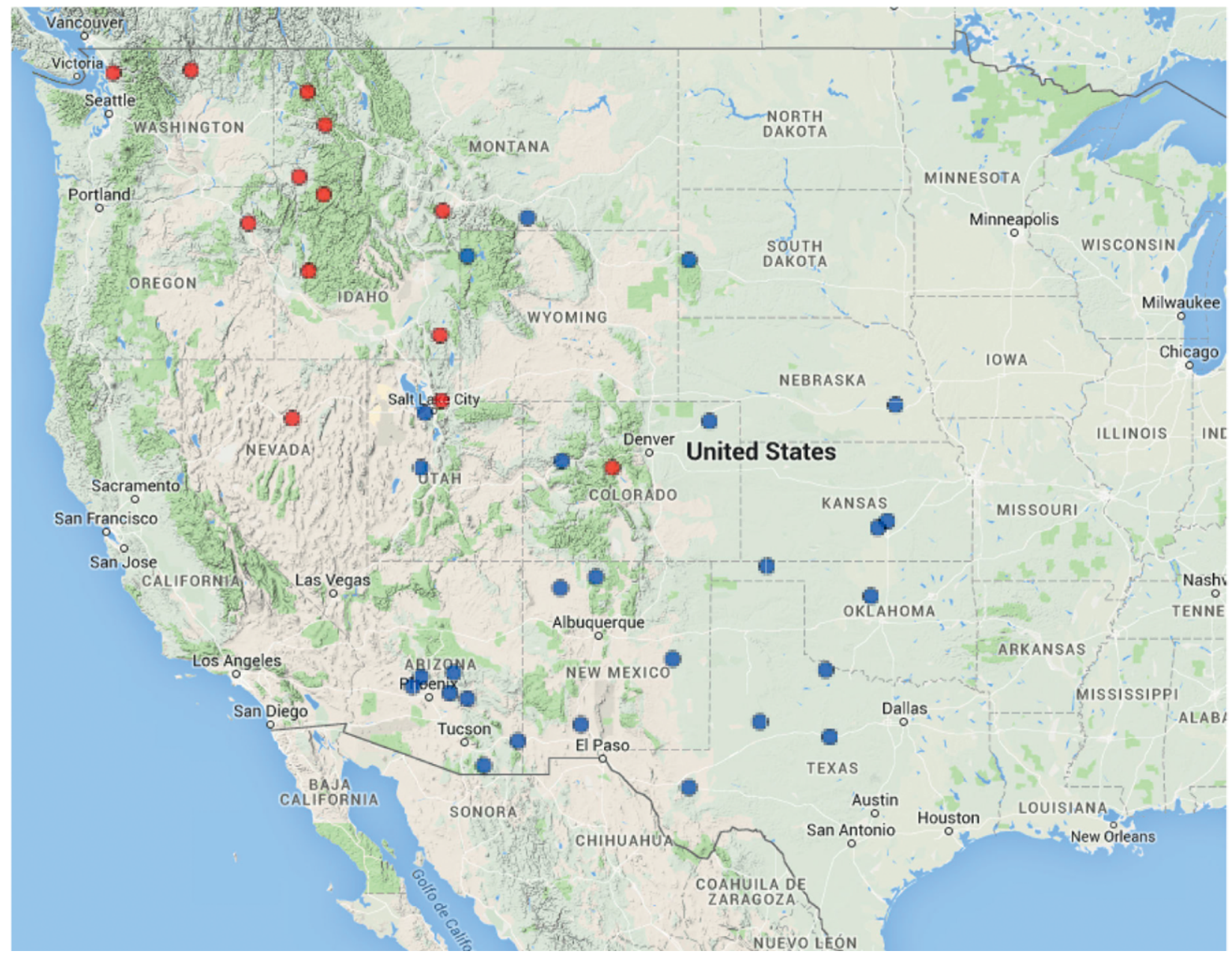

FIG 4. Location of sites with the most pronounced seasonal differences in rainfall feedback among the 1,250 sites analyzed. Sites considered to have pronounced seasonal differences had values of $F \geq 0.5$ in one season and negative values of $F$ in the counter season that were at least $I$ unit of $F$ different from the former season. Sites indicated with red circles had strongly positive rainfall feedback in the spring-summer season and negative rainfall feedback in the fall-winter season, where $F_{\mathrm{Apr} \text {-Sept }} \geq 0.5$ and $F_{\mathrm{Apr}-\text { Sept }}-F_{\mathrm{O}} \mathrm{Oct-Mar} \geq I$. Sites indicated with blue circles had strongly positive rainfall feedback in the fall-winter season and negative rainfall feedback in the spring-summer season where $F_{\text {oct-Mar }} \geq 0.5$ and $F_{\text {oct-Mar }}-F_{\text {Apr-Sept }} \geq I$. The map was made with GPS visualizer (www.gpsvisualizer.com/) using the Google Terrain maps background.

There are several possible ways in which prolonged increases in cloud-active aerosols can occur (Fig. 5). First, rainfall triggers the growth of microorganisms, some of which subsequently become airborne and can serve as INPs. Those living on plant surfaces include Pseudomonas syringae and other related bacteria (Després et al. 2012; Murray et al. 2012) and rust fungi including Puccina species (Morris et al. 2013). These organisms represent the most efficient INPs in the atmosphere (Morris et al. 2013; Murray et al. 2012). Ice nucleation-active strains of Pseudomonas species are more efficient at $-10^{\circ} \mathrm{C}$ and warmer than all other INPs including inert INPs (i.e., those without any organic matter) by a factor of 1,000 or more, in terms of the number of ice nuclei per surface of particle (see Fig. 18 of Murray et al. 2012). Likewise, based on the size and ice nucleation activity of urediospores of rust fungi (Morris et al. 2013), their efficiency as INPs would be about 100 -fold more than that of inert INPs. Soil and decaying leaf material also harbor fungi such as Mortierella alpina with similar efficiency as INPs (Fröhlich-Nowoisky et al. 2015). For rusts, rain events are critical for dissemination and growth, and are used to predict rust epidemics (Morris et al. 2013, and references therein). For P. syringae, a rapid increase in their population sizes is set off by the impact of 
rain drops on leaves (Hirano et al. 1996), leading to enhanced population sizes on leaves for 10 or more days, consistent with the increases in atmospheric INPs observed after rainfall (Bigg 1958; Bigg et al. 2015). Hirano and colleagues assessed changes in the population sizes of $P$. syringae according to the number of INPs active at $-2.5^{\circ} \mathrm{C}$ that they produce (Hirano et al. 1985), thereby showing that the number of highly active INPs increased 10 -fold within the first day after rain and 1,000-fold within 4 days after rainfall. Although these bacteria can be readily removed from leaf surfaces by wind (Lindemann et al. 1982), the fraction that actually becomes airborne is unknown. Active discharge of fungal spores and associated liquids from spore sacks is also favored by rain or high humidity (Elbert et al. 2007). Hence, rain and the subsequent damp soil following rain could encourage successive cycles of fungal spore generation and emissions leading to intermittent and slowly decreasing emissions as the soil dried out.

A second process involves rainfall-triggering phenomena that can lead to the creation of new INPs. Small ( 100-nm diameter) particles active as INPs in leaf litter can attach to soil particles that later become airborne (Schnell and Vali 1976), a process confirmed via laboratory experiments (Augustin-Bauditz et al. 2015) leading to particles with the same ice nucleating efficiency as observed in organic soils (Conen et al. 2011; O'Sullivan et al. 2014). Ice nucleation-active materials can be released from bacterial vesicles and cell fragments (Phelps et al. 1986), proteinaceous material, and nanoparticles from soil-borne fungi (Fröhlich-Nowoisky et al. 2015; O'Sullivan et al. 2015). Hence, rainfall could lead to microbial growth and fragmentation or wash-off of ice nucleation-active compounds that could subsequently adhere to soil or other fine particulate matter and be lofted into the atmosphere (O'Sullivan et al. 2015).

Additionally, aerosols that are formed by the condensation of gas-phase compounds (called new particle formation, NPF) also increase after rainfall (Bigg 2004; Creamean et al. 2011) and grow to sizes that can function as CCN (Merikanto et al. 2009). Microorganisms release volatile organic compounds (VOCs) that can foster NPF via the conversion of the gas phase of these biogenic compounds to particles (Kulmala et al. 2004). This is in part due to the scavenging of aerosols by falling precipitation, creating relatively clean conditions for gas-phase species to form new particles as compared to condensing onto preexisting particles (Bigg 2004; Creamean et al. 2011). NPF is the most important factor contributing to particle number concentration in the atmosphere (Riccobono et al. 2014). Microbial activity is responsible for the emission of organic compounds from litter (Leff and Fierer 2008), and this emission has been observed to increase markedly after a rain event (Greenberg et al. 2012). Increases in NPF in forests can continue for up

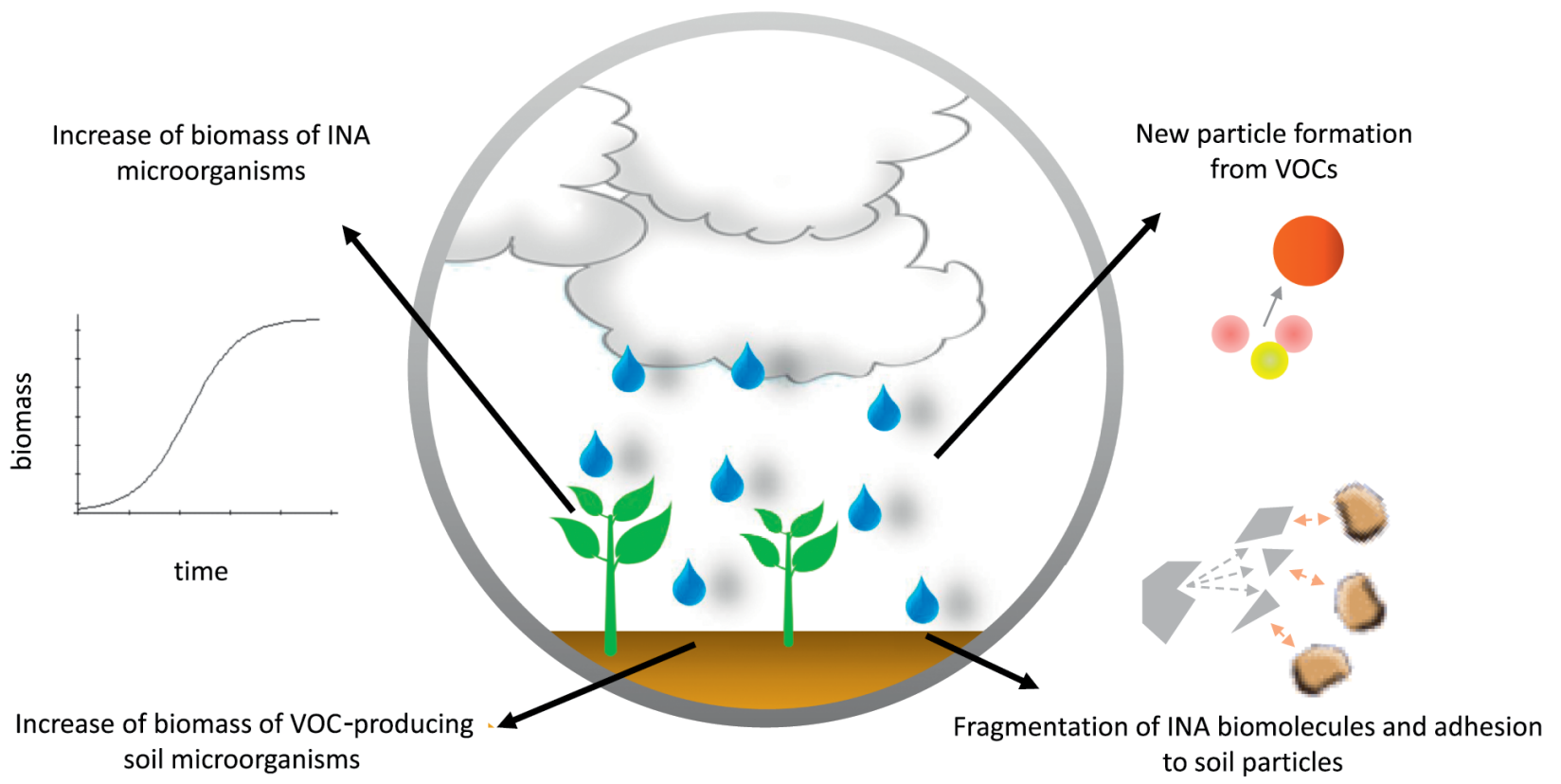

FIG 5. Sources of cloud-active aerosols that can persist in the atmosphere after rainfall. 
to 4 days after a rain event, probably due to prolonged emission of biogenic compounds by microorganisms in pine needle litter that are stimulated by rainfall (Bigg 2004).

SUMMARY AND PERSPECTIVES. Based on a time-series analysis of rainfall leading up to and following key rainfall events that are known to stimulate persistent increases of airborne INPs and other cloud-active aerosols, we have developed a tool to help identify the conditions under which aerosols have important effects on the outcome of meteorological contexts that are favorable for rainfall. This tool consists of open-source software for calculation of rainfall feedback indices and a website where maps of the indices can be explored. As argued above, there is a strong foundation from field observations of aerosol behavior and from environmental microbiology to justify investigating the role of biological aerosols in persistent effects of rainfall on subsequent rainfall. Therefore, this tool provides a means to explore the roles of biological aerosols, in particular, in rainfall. From the observations about trends in $F$ that we observed, we have developed a series of hypotheses about the underlying biological phenomena, and we suggest a framework for generating more such hypotheses (http://biorxiv.org/content/early/2016/08/21/070532). Tackling such hypotheses would require the deployment of microbiological techniques sensu stricto (i.e., techniques to identify, quantify, and characterize the specific microorganisms involved), and would herald in a new era of interdisciplinary research.

The software, maps, and open-source website we describe are a rich and readily exploitable resource to develop rationale for choosing cohorts of experimental sites to elucidate the impact of aerosols on rainfall under specific land surface and source emission conditions. The resulting research could provide data that lead to the integration of a rational parameterization of aerosol effects into precipitation forecasting models. Furthermore, use of rainfall feedback maps and the overall approach we describe here will reveal the importance of land use as it relates to rainfall because of the major role of plants and agriculture as sources of biological INPs and other biological aerosols. There is increasing awareness that human activities that generate aerosols have marked impacts on precipitation (Levin and Cotton 2008), as do changes in land cover (Pielke et al. 2007). Hence, mapping rainfall feedback could help elucidate the effects of agriculture, urban centers, forests, industrial centers, and other types of land use on rainfall, thereby raising prospects for rational management of their impact on rainfall.

ACKNOWLEDGMENTS. This work was supported by in-house funds from INRA and Montana State University and the personal resources of E. K. Bigg. Publication fees were covered by US NSF Dimensions of Biodiversity Program grant 1241054 (RAINS). We thank meteorologist Robert Zamora and Paul Neiman of NOAA for informative discussion.

\section{FOR FURTHER READING}

Augustin-Bauditz, S., and Coauthors, 2015: The immersion freezing behavior of mineral dust particles mixed with biological substances. Atmos. Chem. Phys. Discuss., 15, 29 639-29 671, doi:10.5194/acpd -15-29639-2015.

Bigg, E. K., 1958: A long period fluctuation in freezing nucleus concentrations. J. Meteor., 15, 561-562, doi:10.1175/1520-0469(1958)015<0561:ALPFIF $>2.0 . \mathrm{CO} ; 2$.

— 2004: Gas emissions from soil and leaf litter as a source of new particle formation. Atmos. Res., 70, 33-42, doi:10.1016/j.atmosres.2003.10.003.

—, S. Soubeyrand, and C. E. Morris, 2015: Persistent after-effects of heavy rain on concentrations of ice nuclei and rainfall suggest a biological cause. Atmos. Chem. Phys., 15, 2313-2326, doi:10.5194/acp-15 -2313-2015.

Chilès, J. P., and P. Delfiner, 1999: Geostatistics-Modeling Spatial Uncertainty. John Wiley \& Sons, 695 pp.

Conen, F., C. E. Morris, J. Leifeld, M. V. Yakutin, and C. Alewell, 2011: Biological residues define the ice nucleation properties of soil dust. Atmos. Chem. Phys., 11, 9643-9648 doi:10.5194/acp-11-9643-2011.

Creamean, J. M., A. P. Ault, J. E. Ten Hoeve, M. Z. Jacobson, G. C. Roberts, and K. A. Prather, 2011: Measurements of aerosol chemistry during new particle formation events at a remote rural mountain site. Environ. Sci. Technol., 45, 8208-8216, doi:10.1021 les103692f.

—, — - A. B. White, P. J. Neiman, F. M. Ralph, P. Minnis, and K. A. Prather, 2015: Impact of interannual variations in sources of insoluble aerosol species on orographic precipitation over California's central Sierra Nevada. Atmos. Chem. Phys., 15, 6535-6548, doi:10.5194/acp-15-6535-2015. 
Després, V. R., and Coauthors, 2012: Primary biological aerosol particles in the atmosphere: A review. Tellus, 64B, 015598, doi:10.3402/tellusb.v64i0.15598.

Dettinger, M., 2011: Climate change, atmospheric rivers, and floods in California: A multimodel analysis of storm frequency and magnitude changes. J. Amer. Water Resour. Assoc., 47, 514-523, doi:10.1111/j.1752 -1688.2011.00546.x.

Elbert, W., P. E. Taylor, M. O. Andreae, and U. Pöschl, 2007: Contribution of fungi to primary biogenic aerosols in the atmosphere: Wet and dry discharged spores, carbohydrates, and inorganic ions. Atmos. Chem. Phys., 7, 4569-4588, doi:10.5194/acp-7-4569-2007.

Fröhlich-Nowoisky, J., T. C. J. Hill, B. G. Pummer, P. Yordanova, G. D. Franc, and U. Pöschl, 2015: Ice nucleation activity in the widespread soil fungus Mortierella alpina. Biogeosciences, 12, 1057-1071, doi:10.5194/bg-12-1057-2015.

Greenberg, J. P., D. Asensio, A. Turnipseed, A. B. Guenther, T. Karl, and D. Gochis, 2012: Contribution of leaf and needle litter to whole ecosystem BVOC fluxes. Atmos. Environ., 59, 302-311, doi:10.1016/j. atmosenv.2012.04.038.

Grossmann, E. B., J. S. Kagan, J. A. Ohmann, H. May, M. J. Gregory, and C. Tobalske, 2008: The Pacific Northwest regional GAP analysis project: Final report on Land Cover Mapping Methods, Map Zones 2 and 7, PNW ReGAP. Institute for Natural Resources, Oregon State University, $66 \mathrm{pp}$.

Guan, B., D. E. Waliser, N. P. Molotch, E. J. Fetzer, and P. J. Neiman, 2012: Does the Madden-Julian oscillation influence wintertime atmospheric rivers and snowpack in the Sierra Nevada? Mon. Wea. Rev., 140, 325-342, doi:10.1175/MWR-D-11-00087.1.

Hart, J. F., 2001: Half a century of cropland change. Geogr. Rev., 91, 525-543, doi:10.2307/3594739.

Hayhoe, K., and Coauthors, 2004: Emissions pathways, climate change, and impacts on California. Proc. Natl. Acad. Sci. USA, 101, 12 422-12 427, doi:10.1073 /pnas.0404500101.

Hirano, S. S., L. S. Baker, and C. D. Upper, 1985: Ice nucleation temperature of individual leaves in relation to population sizes of ice nucleation active bacteria and frost injury. Plant Physiol., 77, 259-265, doi:10.1104/pp.77.2.259.

— - — , and — 1996: Raindrop momentum triggers growth of leaf-associated populations of Pseudomonas syringae on field-grown snap bean plants. Appl. Environ. Microbiol., 62, 2560-2566.

Huffman, J. A., and Coauthors, 2013: High concentrations of biological aerosol particles and ice nuclei during and after rain. Atmos. Chem. Phys., 13, 61516164, doi:10.5194/acp-13-6151-2013.

Kulmala, M., and Coauthors, 2004: A new feedback mechanism linking forests, aerosols, and climate. Atmos. Chem. Phys., 4, 557-562, doi:10.5194/acp-4-557-2004.

Leff, J. W., and N. Fierer, 2008: Volatile organic compound (VOC) emissions from soil and litter samples. Soil Biol. Biochem., 40, 1629-1636, doi:10.1016/j .soilbio.2008.01.018.

Letcher, T., and W. R. Cotton, 2014: The effect of pollution aerosol on wintertime orographic precipitation in the Colorado Rockies using a simplified emissions scheme to predict CCN concentrations. J. Appl. Meteor. Climatol., 53, 859-872, doi:10.1175/JAMC-D-13-0166.1.

Levin, Z., and W. R. Cotton, Eds., 2008: Aerosol Pollution Impact on Precipitation: A Scientific Review. Springer, $386 \mathrm{pp}$.

Lindemann, J., H. A. Constantinidiou, W. R. Barchet, and C. D. Upper, 1982: Plants as source of airborne bacteria, including ice nucleation-active bacteria. Appl. Environ. Microbiol., 44, 1059-1063.

Merikanto, J., D. V. Spracklen, G. W. Mann, S. J. Pickering, and K. S. Carslaw, 2009: Impact of nucleation on global CCN. Atmos. Chem. Phys., 9, 8601-8616, doi:10.5194/acp-9-8601-2009.

Morris, C. E., and Coauthors, 2013: Urediospores of rust fungi are ice nucleation active at $>-10^{\circ} \mathrm{C}$ and harbor ice nucleation active bacteria. Atmos. Chem. Phys., 13, 4223-4233, doi:10.5194/acp-13-4223-2013.

Murray, B. J., D. O'Sullivan, J. D. Atkinson, and M. E. Webb, 2012: Ice nucleation by particles immersed in supercooled cloud droplets. Chem. Soc. Rev., 41, 6519-6554, doi:10.1039/c2cs35200a.

O'Sullivan, D., and Coauthors, 2014: Ice nucleation by fertile soil dusts: Relative importance of mineral and biogenic components. Atmos. Chem. Phys., 14, 1853-1867, doi:10.5194/acp-14-1853-2014.

— and Coauthors, 2015: The relevance of nanoscale biological fragments for ice nucleation in clouds. Sci. Rep., 5.

Pandey, G. R., D. R. Cayan, and K. P. Georgakakos, 1999: Precipitation structure in the Sierra Nevada of California during winter. J. Geophys. Res., 104, 12 019-12 030, doi:10.1029/1999JD900103.

Phelps, P., T. H. Giddings, M. Prochoda, and R. Fall, 1986: Release of cell-free ice nuclei by Erwinia herbicola. J. Bacteriol., 167, 496-502.

Phillips, V. T. J., and Coauthors, 2009: Potential impacts from biological aerosols on ensembles of continental clouds simulated numerically. Biogeosciences, $\mathbf{6}$, 987-1014, doi:10.5194/bg-6-987-2009. 
Pielke, R. A., and Coauthors, 2007: An overview of regional land-use and land-cover impacts on rainfall. Tellus, 59E, 587-601, doi:10.1111/j.1600-0889.2007.00251.x.

Ralph, F. M., T. Coleman, P. J. Neiman, R. J. Zamora, and M. D. Dettinger, 2013: Observed impacts of duration and seasonality of atmospheric-river landfalls on soil moisture and runoff in coastal northern California. J. Hydrometeor., 14, 443-459, doi:10.1175 /JHM-D-12-076.1.

Rauber, R. M., 1992: Microphysical structure and evolution of a central Sierra Nevada orographic cloud system. J. Appl. Meteor., 31, 3-24, doi:10.1175/1520 -0450(1992)031<0003:MSAEOA>2.0.CO;2.

Riccobono, F., and Coauthors, 2014: Oxidation products of biogenic emissions contribute to nucleation of atmospheric particles. Science, 344, 717-721, doi:10.1126/science.1243527.

Rosenfeld, D., W. L. Woodley, D. Axisa, E. Freud, J. G. Hudson, and A. C. D. Givati, 2008: Aircraft measurements of the impacts of pollution aerosols on clouds and precipitation over the Sierra Nevada. J. Geophys. Res., 113, D15203, doi:10.1029/2007JD009544.

Schnell, R. C., and G. Vali, 1976: Biogenic ice nuclei: Part I. Terrestrial and marine sources. J. Atmos. Sci., 33,
1554-1564, doi:10.1175/1520-0469(1976)033<1554:BI NPIT>2.0.CO;2.

Soubeyrand, S., C. E. Morris, and E. K. Bigg, 2014: Analysis of fragmented time directionality in time series to elucidate feedbacks in climate data. Environ. Modell. Software, 61, 78-86, doi:10.1016/j .envsoft.2014.07.003.

Stopelli, E., F. Conen, C. E. Morris, E. Hermann, N. Bukowiecki, and C. Alewell, 2015: Ice nucleation active particles are efficiently removed by precipitating clouds. Sci. Rep., 5, 16433, doi:10.1038/srep16433.

Tuttle, S., and G. Salvucci, 2016: Empirical evidence of contrasting soil moisture-precipitation feedbacks across the United States. Science, 352, 825-828, doi:10.1126/science.aaa7185.

Wright, T. P., J. D. Hader, G. R. McMeeking, and M. D. Petters, 2014: High relative humidity as a trigger for widespread release of ice nuclei. Aerosol Sci. Technol., 48, i-v, doi:10.1080/02786826.2014.968244.

Yue, S., H. Ren, S. Fan, Y. Sun, Z. Wang, and P. Fu, 2016: Springtime precipitation effects on the abundance of fluorescent biological aerosol particles and HULIS in Beijing. Sci. Rep., 6, 29618, doi:10.1038/srep29618.

\section{NEW FROM AMS BOOKS!}

\section{"An engrossing account of New England's worst natural catastrophe."}

- KERRY EMANUEL, Professor of Atmospheric Science, MIT

\section{Taken by Storm, 1938:}

\section{A Social and Meteorological History of the Great New England Hurricane} LOURDES B. AVILÉS

When the Great New England Hurricane of 1938 hit the Northeast unannounced, it changed everything from the landscape, to Red Cross and Weather Bureau protocols, to the measure of Great Depression relief New Englanders would receive, and the resulting pace of regional economic recovery. The science behind this storm is presented here for the first time, with new data that sheds light on the motivations of the Weather Bureau forecasters. This compelling history successfully weaves science, historical accounts, and social analyses to create a comprehensive picture of the most powerful and devastating hurricane to hit New England to date.

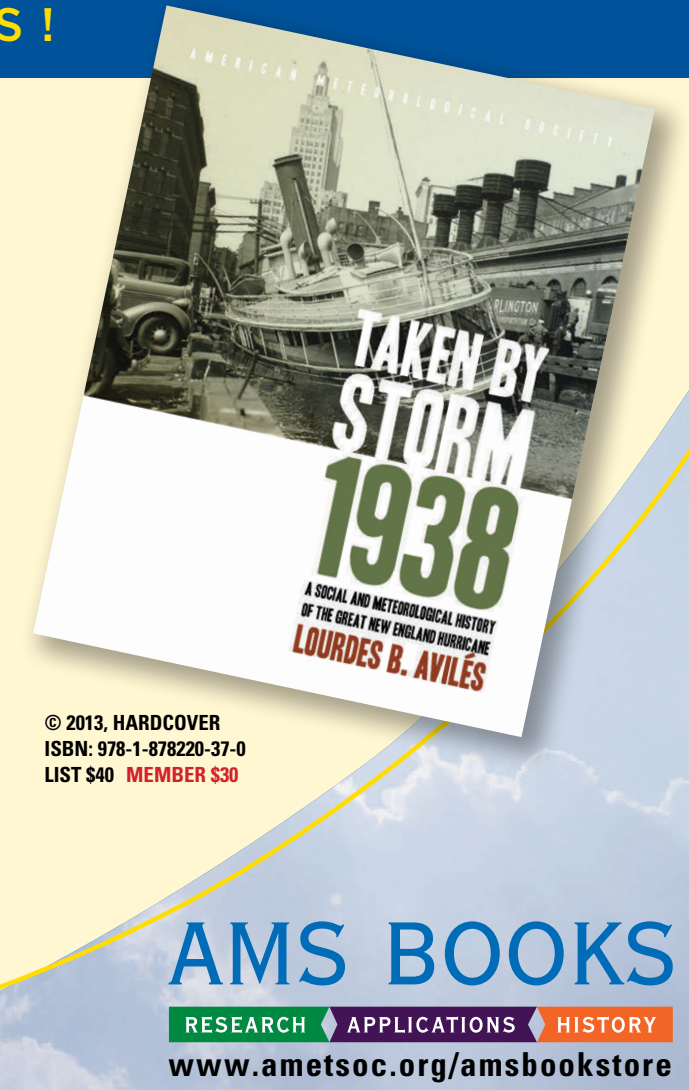

